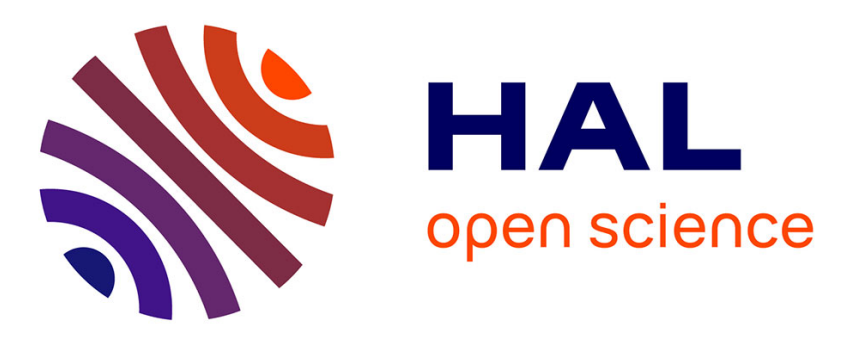

\title{
Experimental and modeling study of the high-temperature combustion chemistry of tetrahydrofurfuryl alcohol
}

Luc-Sy Tran, Hans-Heinrich Carstensen, Kae-Ken Foo, Nathalie Lamoureux, Sylvie Gosselin, Laurent Gasnot, Abderrahman El-Bakali, Pascale Desgroux

\section{To cite this version:}

Luc-Sy Tran, Hans-Heinrich Carstensen, Kae-Ken Foo, Nathalie Lamoureux, Sylvie Gosselin, et al.. Experimental and modeling study of the high-temperature combustion chemistry of tetrahydrofurfuryl alcohol. Proceedings of the Combustion Institute, 2021, Proceedings of the Combustion Institute, 38, pp.631-640. 10.1016/j.proci.2020.07.057 . hal-02960929v2

\section{HAL Id: hal-02960929 \\ https://hal.univ-lille.fr/hal-02960929v2}

Submitted on 7 Nov 2020 (v2), last revised 3 Nov 2021 (v3)

HAL is a multi-disciplinary open access archive for the deposit and dissemination of scientific research documents, whether they are published or not. The documents may come from teaching and research institutions in France or abroad, or from public or private research centers.
L'archive ouverte pluridisciplinaire HAL, est destinée au dépôt et à la diffusion de documents scientifiques de niveau recherche, publiés ou non, émanant des établissements d'enseignement et de recherche français ou étrangers, des laboratoires publics ou privés. 


\title{
Experimental and modeling study of the high-temperature combustion chemistry of tetrahydrofurfuryl alcohol
}

\author{
Luc-Sy Tran ${ }^{1}$, Hans-Heinrich Carstensen ${ }^{2,3}$, Kae Ken Foo ${ }^{1}$, Nathalie Lamoureux ${ }^{1}$, Sylvie Gosselin ${ }^{1}$, \\ Laurent Gasnot ${ }^{1}$, Abderrahman El-Bakali ${ }^{1}$, Pascale Desgroux ${ }^{1}$ \\ ${ }^{1}$ Univ. Lille, CNRS, UMR 8522 - PC2A - Physicochimie des Processus de Combustion et de l'Atmosphère, \\ F-59000 Lille, France \\ ${ }^{2}$ Fundación Agencia Aragonesa para la Investigación y Desarrollo (ARAID), Zaragoza, Spain \\ 3 Department of Chemical and Environmental Engineering, Engineering and Architecture School, \\ University of Zaragoza, Spain
}

\author{
Published in Proceedings of the Combustion Institute \\ https://doi.org/10.1016/j.proci.2020.07.057
}

\begin{abstract}
Lignocellulosic tetrahydrofuranic (THF) biofuels have been identified as promising fuel candidates for spark-ignition (SI) engines. To support the potential use as transportation biofuels, fundamental studies of their combustion and emission behavior are highly important. In the present study, the high-temperature (HT) combustion chemistry of tetrahydrofurfuryl alcohol (THFA), a THF based biofuel, was investigated using a comprehensive experimental and numerical approach.

Representative chemical species profiles in a stoichiometric premixed methane flame doped with $\sim 20 \%$ (molar) THFA at $5.3 \mathrm{kPa}$ were measured using online gas chromatography. The flame temperature was obtained by NO laser-induced fluorescence (LIF) thermometry. More than 40 chemical products were identified and quantified. Many of them such as ethylene, formaldehyde, acrolein, allyl alcohol, 2,3-dihydrofuran, 3,4-dihydropyran, 4-pentenal, and tetrahydrofuran-2carbaldehyde are fuel-specific decomposition products formed in rather high concentrations. In the numerical part, as a complement to kinetic modeling, high-level theoretical calculations were performed to identify plausible reaction pathways that lead to the observed products. Furthermore, the rate coefficients of important reactions and the thermochemical properties of the related species were calculated. A detailed kinetic model for high-temperature combustion of THFA was developed, which reasonably predicts the experimental data. Subsequent rate analysis showed that THFA is mainly consumed by $\mathrm{H}$-abstraction reactions yielding several fuel radicals that in turn undergo either $\beta$-scission reactions or intramolecular radical addition that effectively leads to ring enlargement. The importance of specific reaction channels generally correlates with bond dissociation energies. Along THFA reaction routes, the derived species with cis configuration were found to be thermodynamically more stable than their corresponding trans configuration, which differs from usual observations for hydrocarbons.
\end{abstract}

Keywords: Biofuel, tetrahydrofurfuryl alcohol, premixed flame, gas chromatography, detailed kinetic model. 


\section{Introduction}

Production of renewable energy through biofuel combustion is increasing, contributing to mitigating climate change and enhancing energy security. Tetrahydrofurfuryl alcohol (THFA, $\mathrm{C}_{5} \mathrm{H}_{10} \mathrm{O}_{2}$ ) is the cheapest molecule among the tetrahydrofuran (THF) family of biofuels (e.g. tetrahydrofuran, 2methyltetrahydrofuran, 2,5-dimethyltetrahydrofuran). It can be easily produced via hydrogenation of furfural which is accessible from lignocellulosic biomass [1,2]. This biofuel family has been extensively investigated in terms of productions, engine performance, and combustion chemistry [36]. For THFA, studies on production methods [1,2], atomization/spray propagation [7], ignition characteristics [8] are known, and it has been suggested as a biofuel candidate for SI engines [8]. The hydroxyl group could lend THFA better anti-knock characteristic compared to other THF fuels. According to our knowledge, species profiles of the THFA combustion have not been reported while they are of high value to improve our understanding of the combustion process and related pollutant emissions. We have thus studied the combustion of this fuel using a comprehensive approach that includes: (i) a dedicated experimental flame setup allowing to measure a large number of oxygenated and non-oxygenated stable species and (ii) theoretical analyses covering the development of a new detailed kinetic model based on both experimental observations and high-level ab initio calculations.

\section{Experimental and computational methods}

\subsection{Flame species measurements}

A stoichiometric premixed flame of THFA $/ \mathrm{CH}_{4} / \mathrm{O}_{2} / \mathrm{N}_{2}(1.5 \% / 6.1 \% / 21.7 \% / 70.7 \%)$ was stabilized on a McKenna burner ( $60 \mathrm{~mm}$ diameter) at $5.3 \mathrm{kPa}$, with a cold gas velocity $\left(333 \mathrm{~K}, 5.3 \mathrm{kPa}\right.$ ) of $68 \mathrm{~cm} \mathrm{~s}^{-1}$ and an overall mass flow rate of $3.81 \times 10^{-3} \mathrm{~g} \mathrm{~cm}^{-2} \mathrm{~s}^{-1}$. The use of a mixture flame was necessary because a comparable pure THFA flame was unstable due to its high boiling point $\left(178{ }^{\circ} \mathrm{C}\right) . \mathrm{CH}_{4}$ was chosen to be a hydrocarbon base fuel due to its well-known combustion chemistry. Furthermore, it produces only small products, making THFA-specific products readily distinguishable.

Flow rates of $\mathrm{CH}_{4}, \mathrm{O}_{2}$ and $\mathrm{N}_{2}$ (purity $299.99 \%$ ) were controlled using mass flow controllers (Bronkhorst, error $\pm 0.5 \%$ ). The flow rate of the liquid THFA (Sigma-Aldrich, purity $\geq 99 \%$ ) was controlled using a Coriolis flow controller (Bronkhorst, error $\pm 0.2 \%$ ) followed by an evaporator.

Gas samples were extracted from the flame using a quartz probe $\left(250 \mu \mathrm{m}\right.$ orifice, $0.9 \mathrm{~mm}$ tip, $22^{\circ}$ opening angle along $15 \mathrm{~mm}$ length, then $7 \mathrm{~mm}$ outer diameter along $50 \mathrm{~mm}$ ), then directed through a heated tube into the GC instruments for online analysis. The used probe slightly affects the position of temperature and species profiles, which made it necessary to moderately shift the temperature profile in the simulations (see Section 3.2). The GC systems were equipped with three columns (RtQBond, MS5A, HayeSep Q) and three detectors, i.e. a thermal conductivity detector (TCD), a flame ionization detector (FID) coupled with a methanizer, and a mass spectrometric detector (MS) with electron ionization at $70 \mathrm{eV}$. Stable species were identified by their individual retention times and MS spectra. Calibration factors were determined using cold-gas mixtures when available. For other species, the calibration factors of corresponding alkanes were used. This assignment relies on the hydrogenation by the methanizer. This procedure has been successfully used before [9]. $\mathrm{H}_{2} \mathrm{O}$ mole fractions were calculated from either $\mathrm{H}$ or $\mathrm{O}$ balance, which lead to values that agreed to within 2$10 \%$. The average value is finally reported. The estimated uncertainties of the GC experiment are $<15 \%$ for main species, $<25 \%$ for abundant intermediates, and $<55 \%$ for minor products $(<10 \mathrm{ppm}$ ). The carbon balance of the flame data was calculated to be $100 \pm 2 \%$.

\subsection{Temperature measurements}

Flame temperatures were measured using NO-LIF thermometry. A small amount of NO (120 ppm in volume fraction) was seeded into the flame without any chemical disturbance to provide a high signal-to-noise ratio. Details concerning the laser and data acquisition systems have been reported previously [10]. Briefly, the laser was tuned over $225.65-225.73 \mathrm{~nm}$ to excite $\mathrm{NO}$ in the A-X(0,0) band. Consequently, the LIF signal collection was done in the $A-X(0,2)$ band of NO, centered at $245 \mathrm{~nm}$. The laser energy was maintained at $40 \mu \mathrm{J}$, within the linear LIF regime. Synthetic LIF 
excitation spectra were calculated with LIFBASE [11] by applying a Voigt profile (15\% Lorentzian) with a spectral resolution of $0.94 \mathrm{~cm}^{-1}$ from 600 to $2000 \mathrm{~K}$ every $20 \mathrm{~K}$. Temperatures were then determined by fitting the synthetic spectra to the experimental data following the principle of least mean squared method, with an estimated error $\pm 100 \mathrm{~K}$ in the burned-gases zone. Temperatures close to the burner surface $(0.25-2 \mathrm{~mm}$ above the burner) were measured using a commercial K-type thermocouple $(250 \mu \mathrm{m}$ diameter) with error $\sim 1 \%$. Corrections for radiative heat losses were not applied because of the low operating temperatures $(<800 \mathrm{~K})$.

\subsection{Theoretical calculations}

To gain insight into the primary steps of THFA combustion, the kinetic parameters of important THFArelated reactions and the thermodynamic properties of the related species were investigated with high-level first principle calculations. Details of the approach are given in [5]. Briefly, electronic structure calculations at the CBS-QB3 level of theory were performed using the Gaussian 16 revision $B$ suite of programs [12]. The resulting molecular information was used to calculate the partition functions and thermodynamic functions of reactants, products, and transition states with methods from statistical mechanics. The electronic energies were converted with the atomization method, corrected for spin-orbit and bond additive error (BAC) [13], to the corresponding heats of formation. B3LYP/6-311G(2d,d,p) level rotational constants and scaled (factor 0.99) harmonic frequencies, except for those that represent internal rotations, were used to calculate the thermal contributions to the enthalpies as well as entropies and heat capacities. Contributions of internal rotors were obtained from solutions of the Schrödinger equation for one-dimensional internal rotation. Hindrance potentials were determined via relaxed scans in which the torsional angle was changed in 10 degrees steps until a complete rotation was achieved. Only rotations with a hindrance barrier less than $12 \mathrm{kcal} / \mathrm{mol}$ are treated as internal rotation. The required reduced moment of inertia was calculated at the $\mathrm{I}^{(2,3)}$ level, following East and Radom [14]. The calculated total entropies contain corrections for the symmetry and the number of optical isomers.

Transition state theory expressed in terms of Gibbs free energies was used to calculate the highpressure limiting rate coefficients of the most significant reactions. Eckart tunneling was taken into account and the individual rate coefficients, obtained between $300 \mathrm{~K}$ and $2500 \mathrm{~K}$ in $50 \mathrm{~K}$ steps, were finally regressed to modified Arrhenius expressions. The estimated uncertainty of the calculated rate coefficients is about a factor of two to three, while those of enthalpies of formation are generally within $1 \mathrm{kcal} / \mathrm{mol}$.

While the authors realize that the high flame temperatures and rather low pressure will cause the rate coefficients of some THFA-related reactions to depend on pressure, a rigorous master-equation treatment would require sufficiently complete potential energy surfaces (PES), which were beyond the scope of this study. Instead, the focus was to identify the most significant reactions in THFA combustion. A full study of the underlying PES including the master-equation analyses would be a challenging research subject on its own.

\section{Model development and simulations}

A detailed kinetic model for THFA high-temperature (HT) combustion has been developed. It does not contain specific THFA low-temperature chemistry, which could be an interesting subject to future research. The complete model consists of 2914 reactions involving 479 species (available in CHEMKIN format in Supplemental Material (SM) 1). The nomenclature and structure of all species discussed in this paper and the ab initio geometries of the studied molecules including cis and trans conformers are available (Tables S1, S2 in SM2). The THFA model is composed of three main parts that were merged manually:

(1) a base mechanism, describing the reactions for $C_{0}-C_{6}$ species. The mechanism used in [5] was adopted as a starting point in the current work because preliminary tests showed that it predicts the species profiles of the base $\mathrm{CH}_{4}$ flame well and it already contains several species that were 
detected in the present THFA flame. The THFA primary and secondary mechanisms, described below, are then newly added. When species or reactions appear in more than one of these mechanisms, then the thermochemical data found in the base mechanism are retained.

(2) a primary mechanism, describing the initial reactions of THFA and derived fuel radicals.

(3) a secondary mechanism, describing consumption reactions of initial stable products from the primary mechanism. Some of these products (e.g. formaldehyde, ethylene, acrolein) are already included in the base mechanism. They are used without alteration. Otherwise, rate coefficients (e.g. for 4-pentenal, tetrahydrofuran-2-carbaldehyde) were determined by analogy to similarly structured species or based on rate rules implemented in the RMG program [15].

The present study focuses on developing the primary mechanism with the aid of theoretical studies of important reactions. The following section describes selected results and the main features of the proposed THFA primary mechanism.

\subsection{THFA high-temperature chemistry identification}

$\mathrm{C}-\mathrm{H}$ bond dissociation energies (BDE) for THFA were calculated at the CBS-QB3 level of theory to gain insight into the properties of this molecule. Furthermore, rate coefficients for $\mathrm{H}$-abstractions from THFA were calculated to understand how BDE differences influence the rate parameters of this important reaction class. Finally, the PES for the decomposition of the main fuel radicals, which play a central role in the THFA HT chemistry were examined to get an overview about their plausible unimolecular consumption pathways. These examinations are important for developing a reliable THFA model. Selected results are presented in Fig. 1.
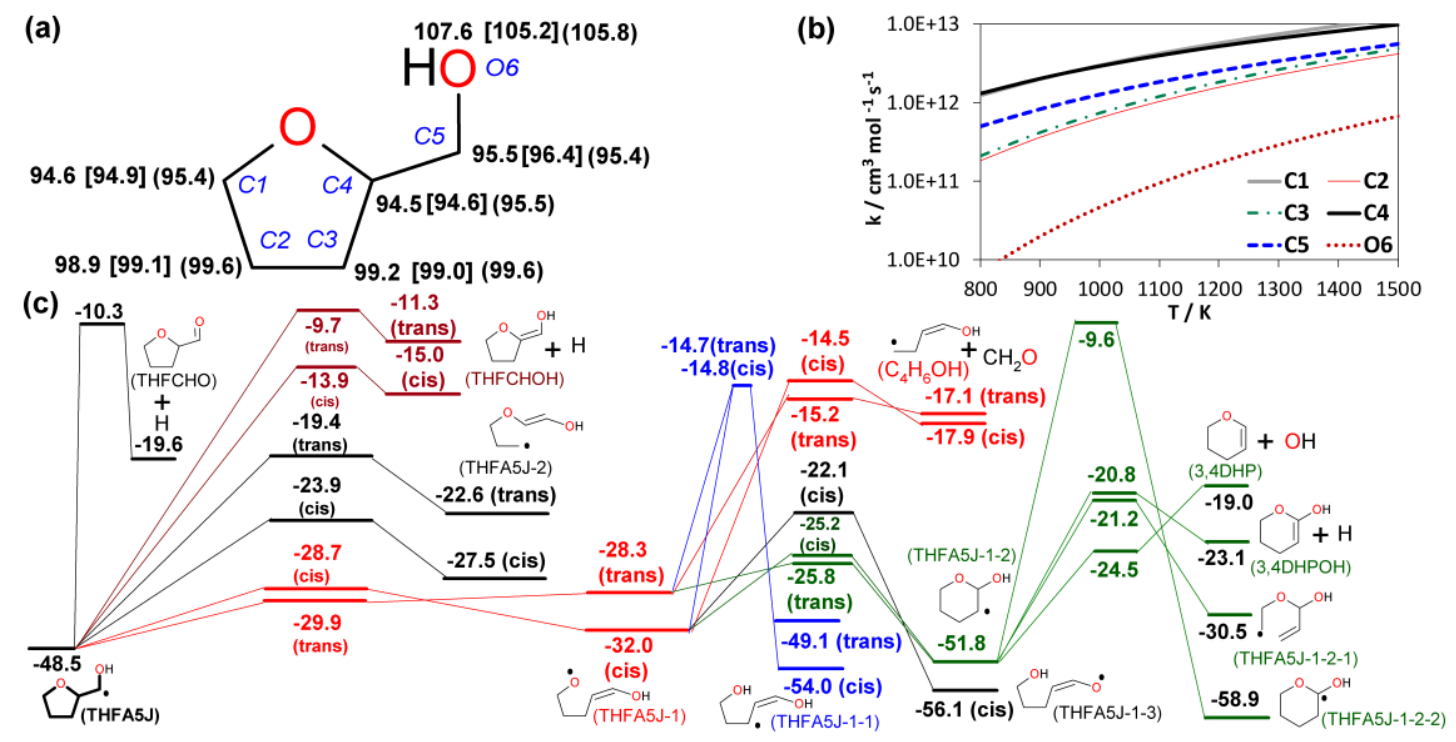

Fig. 1. Selected CBS-QB3 results: (a) THFA structure. Italic font: carbon/oxygen position; bold font: C-H or O-H BDEs in $\mathrm{kcal} / \mathrm{mol}$, in square brackets: CBS-QB3 by [8], in parentheses: RMG's group additivity [15]. (b) Rate coefficients of $\mathrm{H}$ abstractions from THFA by $\mathrm{H}$-atoms as a function of temperature. (c) The potential energy surface for decomposition of the THFA5J (Bold numbers: standard enthalpies of formation in $\mathrm{kcal} / \mathrm{mol}$ without BAC).

Figure 1a shows that $\mathrm{C}-\mathrm{H}$ BDEs at the $\mathrm{C}_{\alpha}$ (next to an oxygen, i.e. $\mathrm{C} 1, \mathrm{C} 4, \mathrm{C} 5$ ) are several $\mathrm{kcal} / \mathrm{mol}$ lower than those at other positions. The computed values are in good agreement (i.e. within 1 $\mathrm{kcal} / \mathrm{mol}$ ) with those previously reported in [8] and those determined by group additivity method in RMG [15], except for O-H BDE, for which the present value $(107.6 \mathrm{kcal} / \mathrm{mol})$ is $\sim 2 \mathrm{kcal} / \mathrm{mol}$ higher. This value is also higher than that of linear alcohols ( $105 \mathrm{kcal} / \mathrm{mol})$. The optimized geometry of THFA shows that the $\mathrm{H}$-atom of $\mathrm{OH}$ is in close proximity to the ether $\mathrm{O}$-atom, creating a strong intramolecular hydrogen bond which increases the BDE of the $\mathrm{O}-\mathrm{H}$ bond.

Figure $1 \mathrm{~b}$ indicates that the rate coefficients for $\mathrm{H}$-abstractions by $\mathrm{H}$ atom at positions $\mathrm{C} 1, \mathrm{C} 4$, and $\mathrm{C} 5$ are the fastest followed by those from the $\mathrm{C} 2$ and $\mathrm{C} 3$ positions. $\mathrm{H}$-abstraction by $\mathrm{H}$ atoms at 
position $\mathrm{O} 6$ is much slower (10-300 times) than those at other positions. These trends correlate well with the differences in BDEs. $\mathrm{H}$-abstractions by other radicals (e.g. $\mathrm{CH}_{3}, \mathrm{OH}, \mathrm{O}$ ) exhibit a similar trend.

$\mathrm{H}$-abstractions at the positions 1 to 6 of THFA produce six different fuel radicals, namely THFA1J, THFA2J, THFA3J, THFA4J, THFA5J, and THFA6J. Because of their special importance, the ring opening pathways of THFA1J, THFA4J, and THFA5J were analyzed in-depth at the CBS-QB3 level of theory and their computed rate coefficients were incorporated into the newly developed model.

Figure 1c presents as an example of the PES for the decomposition of THFA5J. The computed rate coefficients and branching ratio of all considered reaction pathways are available (Fig.S1, SM2). As shown in Fig. 1c, THFA5J reacts by $\mathrm{C}-\mathrm{H}$ or $\mathrm{O}-\mathrm{H} \beta$-scissions to form unsaturated cyclic species, THFCHO and THFCHOH. While THFCHO was detected, its higher energy enol tautomer THFCHOH was not identified in the experiment. Ring opening of THFA5J by $\mathrm{C}-\mathrm{O}$ and $\mathrm{C}-\mathrm{C} \beta$-scissions produces THFA5J-1 and THFA5J-2, respectively. Over the entire flame temperature, the $\mathrm{C}-\mathrm{O} \beta$-scission is energetically favored, forming THFA5J-1, with a barrier about $10 \mathrm{kcal} / \mathrm{mol}$ lower than that for the $\mathrm{C}-\mathrm{C} \beta$-scission (see branching ratio in Fig.S1).

THFA5J-1 reacts by $\mathrm{C}-\mathrm{C} \beta$-scissions to form the $\mathrm{C}_{4} \mathrm{H}_{6} \mathrm{OH}$ radical together with formaldehyde $\left(\mathrm{CH}_{2} \mathrm{O}\right)$ or via isomerization to form the resonance-stabilized THFA5J-1-1 and THFA5J-1-3 radicals (Fig. 1c). THFA5J-1 may also react via intramolecular addition which leads to the 6 -membered cyclic radical THFA5J-1-2. The latter radical has several low energy pathways available including the formation of 3,4DHP (3,4-dihydropyran), which was experimentally detected in high amounts in the present work. The ring enlargement product, THFA5J-1-2, may also produce 3,4DHPOH (Fig. 1c) but it was not experimentally detected. The newly developed kinetic model predicts that this species and $\mathrm{THFCHOH}$ (a THFA5J C-H $\beta$-scission product as discussed above, Fig. 1c) appear in very low concentrations $(<1 \mathrm{ppm})$ which is below the detection limit.

The examination of both cis and trans configurations of the resulting oxygenated species shows that the cis configuration is thermodynamically more stable than the trans configuration, due to possible intramolecular hydrogen bond formed in the oxygenated molecules, which contrasts the ranking usually observed for hydrocarbons. This trend was noted for all oxygenated species computed in the present work (cf. Fig. 1c). (Note: trans THFA5J-1-3 is not shown in Fig. 1c because it is not produced on this PES, but its enthalpy of formation $(-52.3 \mathrm{kcal} / \mathrm{mol})$ is higher than cis THFA5J1-3 $(-56.1 \mathrm{kcal} / \mathrm{mol}))$. A similar trend was experimentally observed for cis and trans 1-propenol [16].

Our general approach is to use thermochemical properties (thermodynamic data and rate coefficients for its reactions) of the lowest energy isomer of any cis/trans pair for the present kinetic model. As a quick test, a few simulations were also performed with thermochemical data belonging to the higher energy isomer. These simulations lead to only insignificant changes in the predictions. For example, the simulation profiles related to major species are superimposed, and those of intermediates are only little affected $(<10 \%)$ as exemplarily shown in Fig. S2 (SM2). These results are expected because at high temperatures small energetic differences become unimportant. In reality, high temperatures in flame enable interconversion of the cis/trans pairs shown in Fig. 1c making those indistinguishable.

\subsection{HT primary mechanism for THFA}

The following classes of elementary reactions have been considered in the THFA primary mechanism:

(i) Unimolecular decomposition of THFA

(ii) $\mathrm{H}$-atom abstractions from THFA by small species $\left(\mathrm{H}, \mathrm{CH}_{3}, \mathrm{OH}, \mathrm{O}, \mathrm{O}_{2}\right.$, etc.) producing the fuel radicals THFA1J, THFA2J, THFA3J, THFA4J, THFA5J, and THFA6J

(iii) Fuel radical decomposition by ring opening to form acyclic fuel radicals

(iv) Fuel radical decomposition at the side chain

(v) Decomposition of the resulting acyclic fuel radicals from (iii)

(vi) Fuel radical ring enlargement

(vii) Fuel radical isomerization

(viii) Reactions of fuel radicals with $\mathrm{O}_{2}$ 
(ix) Fuel radical-radical disproportionation

Representatives for each reaction class are available in SM2 (Table S3) and here only key features are summarized. At the flame conditions studied in this work, the reaction classes $i$, viii, and $i x$ are found to be insignificant. Their rate coefficients were thus simply estimated by analogy to those for 2-methyltetrahydrofuran (MTHF) (because of THF ring and lateral group) and ethanol (because of alcohol function) in the base mechanism [5]. Rate rules [15] were applied for reaction classes for which no analogous rate information was available. Special attention has been paid to the key reactions of the classes ii-vii because they were identified to play a significant role in THFA flame chemistry. Rate coefficients of $\mathrm{H}$-abstractions (class $\mathrm{ii}$ ) from THFA by $\mathrm{H}$-atom and $\mathrm{CH}_{3}$ radical, were calculated at the CBS-QB3 level, while those by $\mathrm{O}$ and $\mathrm{OH}$ were determined through Evans-Polanyi correlations [17] using CBS-QB3 calculated thermodynamic data of the fuel and the fuel radicals. $\mathrm{H}$ abstractions by $\mathrm{O}_{2}$ are less significant at flame conditions, their rate coefficients were thus only estimated based on MTHF and ethanol following the above-mentioned rules. Abstraction reactions from THFA mainly yield radicals THFA1J, THFA4J, and THFA5J. Therefore, rate coefficients of the ring opening reactions of these radicals (class iii) and several subsequent reactions (classes iv-vii) were determined using CBS-QB3 in the present study, complemented with CBS-QB3 results from [5].

Although most thermochemical data of fuel, fuel radicals, and other newly-introduced species were obtained from quantum chemistry calculations, the group additivity method implemented in the RMG program [15] was used for minor species. The CBS-QB3 calculated enthalpy of formation of THFA at $298 \mathrm{~K}$ is $-89.2 \mathrm{kcal} / \mathrm{mol}$, which agrees well with the experimental value of $-88.1 \pm 1.5 \mathrm{kcal} / \mathrm{mol}$ from [18] and $-89.3 \mathrm{kcal} / \mathrm{mol}$ by RMG [15]. Transport properties of newly-introduced species were estimated based on the correlation proposed by Wang and Frenklach [19].

Flame simulations were performed with the module "Premixed Laminar Burner-Stabilized Flame" of CHEMKIN-Pro 2019R1 package [20], using the present kinetic model. The measured flame temperature profile, shifted $0.15 \mathrm{~mm}$ away from the burner surface to obtain a good agreement in position between the simulated and experimental species profiles, was provided as input data for the numerical calculation. Thermal diffusion effects and back diffusion at the inlet boundary were included.

\section{Results and discussions}

More than $40 \mathrm{C}_{0}-\mathrm{C}_{5}$ species were identified and quantified (the complete dataset is available in SM3), providing a useful dataset for kinetic analyses and for a stringent test of the THFA kinetic model. In the following, we focus on reporting important examples.

\subsection{Temperature, fuel and main products}

Figure 2 presents the profiles of the flame temperature $(T)$, the reactants $\left(\mathrm{CH}_{4}, \mathrm{THFA}, \mathrm{O}_{2}\right)$ and major combustion products $\left(\mathrm{CO}_{2}, \mathrm{CO}, \mathrm{H}_{2} \mathrm{O}, \mathrm{H}_{2}\right)$. As expected, the reactant mole fractions decrease, while temperature and product mole fractions increase in the reaction zone (HAB=0-6 mm). The present model reproduces all profiles well, within their uncertainties, regarding both the profile shapes and the absolute mole fractions. Both fuels contribute to the formation of these products. Exemplarily, modeling and experimental analyses reveal that THFA and $\mathrm{CH}_{4}$ contribute to $\mathrm{CO}$ and $\mathrm{CO}_{2}$ formation quite equally, which is consistent with their contribution of carbon in the initial fuel mixture $(55 \%$ and $45 \%$, respectively). 

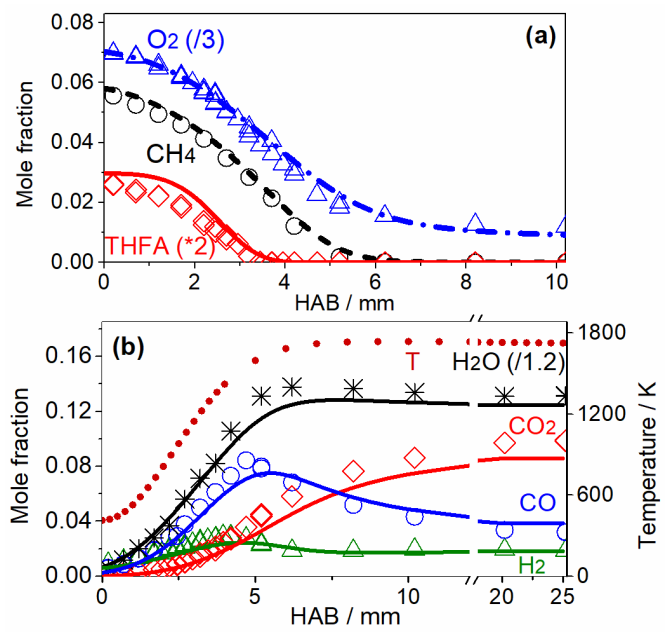

Fig. 2. Mole fraction profiles of reactants (THFA, $\left.\mathrm{CH}_{4}, \mathrm{O}_{2}\right)$ and main products $\left(\mathrm{CO}_{2}, \mathrm{CO}, \mathrm{H}_{2}, \mathrm{H}_{2} \mathrm{O}\right)$ as a function of the height above the burner (HAB). Symbols: experiments, lines: present model. For clarity, the indicated division factors have been used (for both experiment and model) for $\mathrm{O}_{2}$, THFA and $\mathrm{H}_{2} \mathrm{O}$.

\subsection{Intermediate species pool}

\subsubsection{Experimentally detected intermediates}

The maximum mole fractions of detected intermediates are summarized in Fig. 3 . These species consist of $\mathrm{C}_{1}-\mathrm{C}_{5}$ hydrocarbons (12 species) and oxygenates (23 species) with molar masses ranging from 26 to 100. They include numerous isomeric intermediates such as $\mathrm{C}_{3} \mathrm{H}_{4}$ (mass 40, two isomers), $\mathrm{C}_{2} \mathrm{H}_{6} \mathrm{O}$ (mass 46, two isomers), $\mathrm{C}_{4} \mathrm{H}_{8}$ (mass 56, two isomers), $\mathrm{C}_{4} \mathrm{H}_{10}$ (mass 58 , two isomers), $\mathrm{C}_{3} \mathrm{H}_{6} \mathrm{O}$ (mass 58 , four isomers), $\mathrm{C}_{4} \mathrm{H}_{6} \mathrm{O}$ (mass 70 , four isomers), $\mathrm{C}_{4} \mathrm{H}_{8} \mathrm{O}$ (mass 72 , two isomers), $\mathrm{C}_{5} \mathrm{H}_{8} \mathrm{O}$ (mass 84, two isomers), and $\mathrm{C}_{5} \mathrm{H}_{10} \mathrm{O}$ (mass 86 , two isomers). The experimental analysis method used in this work was able to distinguish hydrocarbon and oxygenated species of the highly complex compositions, e.g. species at masses 58 (6 species) and 70 (5 species) (Fig. 3). Note that products of a pure $\mathrm{CH}_{4}$ flame were also measured at identical conditions, showing that high molecular weight species (mass $>46$ ) are not present in measurable amounts. These species are thus dominantly produced from THFA and many of them are identified as THFA-specific intermediates as will be discussed in the following section.

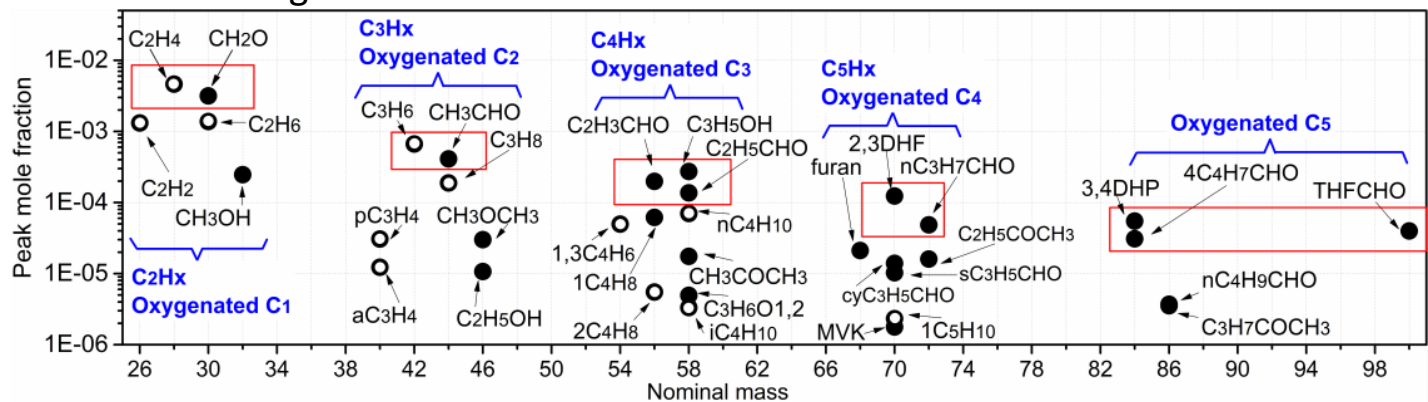

Fig. 3. Summary of maximum mole fraction of 35 experimentally detected intermediates in the studied flame. Open symbols: hydrocarbons, closed symbols: oxygenates. While the identities of light species should be clear, those for the species with mass $>46$ are presented in Table 1.

Table 1. Nomenclature and structure of species with mass $>46$ of Fig. 3

\begin{tabular}{|l|l|l|l|}
\hline Nomenclature & Structure & Nomenclature & Structure \\
\hline $1,3 \mathrm{C}_{4} \mathrm{H}_{6}$ & & $2,3 \mathrm{DHF}$ & \\
\hline $1 \mathrm{C}_{4} \mathrm{H}_{8}$ & & $\mathrm{MVK}$ & \\
\hline $2 \mathrm{C}_{4} \mathrm{H}_{8}$ & $\curvearrowright$ & $\mathrm{cyC}_{3} \mathrm{H}_{5} \mathrm{CHO}$ & \\
\hline $\mathrm{C}_{2} \mathrm{H}_{3} \mathrm{CHO}$ & $\curvearrowright 0$ & $\mathrm{sC}_{3} \mathrm{H}_{5} \mathrm{CHO}$ & \\
\hline $\mathrm{nC}_{4} \mathrm{H}_{10}$ & $\sim$ & $\mathrm{nC}_{3} \mathrm{H}_{7} \mathrm{CHO}$ & \\
\hline
\end{tabular}




\begin{tabular}{|c|c|c|c|}
\hline $\mathrm{C}_{3} \mathrm{H}_{6} \mathrm{O} 1,2$ & O & $\mathrm{C}_{2} \mathrm{H}_{5} \mathrm{COCH}_{3}$ & \\
\hline $\mathrm{C}_{2} \mathrm{H}_{5} \mathrm{CHO}$ & $=0$ & $3,4 \mathrm{DHP}$ & \\
\hline $\mathrm{CH}_{3} \mathrm{COCH}_{3}$ & 0 & $4 \mathrm{C}_{4} \mathrm{H}_{7} \mathrm{CHO}$ & \\
\hline $\mathrm{C}_{3} \mathrm{H}_{5} \mathrm{OH}$ & $\mathrm{OH}$ & $\mathrm{C}_{3} \mathrm{H}_{7} \mathrm{COCH}_{3}$ & \\
\hline Furan & $\left.\llbracket{ }^{\circ}\right\rangle$ & $\mathrm{nC}_{4} \mathrm{H}_{9} \mathrm{CHO}$ & \\
\hline $1 \mathrm{C}_{5} \mathrm{H}_{10}$ & $\gamma$ & THFCHO & \\
\hline
\end{tabular}

The stable intermediates are classified into five groups based on molecular weight criteria. Two or three abundant species are identified in each group (highlighted with a solid square in Fig. 3), based on their peak mole fraction to be within a factor of 3 compared to the most abundant species in their respective mass group. In the first group $\left(\mathrm{C}_{2} \mathrm{H}_{x}\right.$ and oxygenated $\mathrm{C}_{1}$ species), the two most abundant intermediates are $\mathrm{C}_{2} \mathrm{H}_{4}$ (ethylene) and $\mathrm{CH}_{2} \mathrm{O}$ (formaldehyde). $\mathrm{C}_{3} \mathrm{H}_{6}$ (propene) and $\mathrm{CH}_{3} \mathrm{CHO}$ (acetaldehyde) are two dominant species in the second group $\left(\mathrm{C}_{3} \mathrm{H}_{x}\right.$ and oxygenated $\mathrm{C}_{2}$ species), while $\mathrm{C}_{2} \mathrm{H}_{3} \mathrm{CHO}$ (acrolein), $\mathrm{C}_{3} \mathrm{H}_{5} \mathrm{OH}$ (allyl alcohol), and $\mathrm{C}_{2} \mathrm{H}_{5} \mathrm{CHO}$ (propanal) are the major representatives of the third group $\left(\mathrm{C}_{4} \mathrm{H}_{x}\right.$ and oxygenated $\mathrm{C}_{3}$ species). In the fourth group $\left(\mathrm{C}_{5} \mathrm{H}_{x}\right.$ and oxygenated $\mathrm{C}_{4}$ species), 2,3DHF (2,3-dihydrofuran) and $\mathrm{nC}_{3} \mathrm{H}_{7} \mathrm{CHO}$ (butanal) dominate, and 3,4DHP (3,4dihydropyran), $4 \mathrm{C}_{4} \mathrm{H}_{7} \mathrm{CHO}$ (4-pentenal), and THFCHO (tetrahydrofuran-2-carbaldehyde) are the key representatives of the fifth group (oxygenated $C_{5}$ species). Because of their high concentration, they are likely THFA-specific decomposition intermediates and could play important roles in the THFA combustion chemistry. Note that some of them are toxic such as $\mathrm{C}_{3} \mathrm{H}_{5} \mathrm{OH}, \mathrm{C}_{2} \mathrm{H}_{3} \mathrm{CHO}, \mathrm{CH}_{3} \mathrm{CHO}$, and $\mathrm{CH}_{2} \mathrm{O}$. Reliable predictions of their formation along with a good understanding of THFA reaction mechanism are thus important especially for health-concerns.

\subsubsection{Experiment/model comparison and fuel-specific decomposition analysis}

In general, the new kinetic model predicts very well the fuel consumption, the formation of major products (Section 4.1) and stable intermediates. Selected comparisons are shown below; other species profiles are available in SM2 (Figs S3, S4). Although some discrepancies between the model predictions and experimental data are noted, which could result from uncertainties in experimental/kinetic data, pressure effects, and potentially omitted reaction pathways (e.g. wellskipping reactions), the present model exhibits an overall good predictive capability lending confidence in analyzing the major chemistry of THFA combustion. Figure 4 presents the main THFA consumption pathways in the studied flame. Mole fraction profiles of selected fuel-specific decomposition products are presented in Fig. 5.

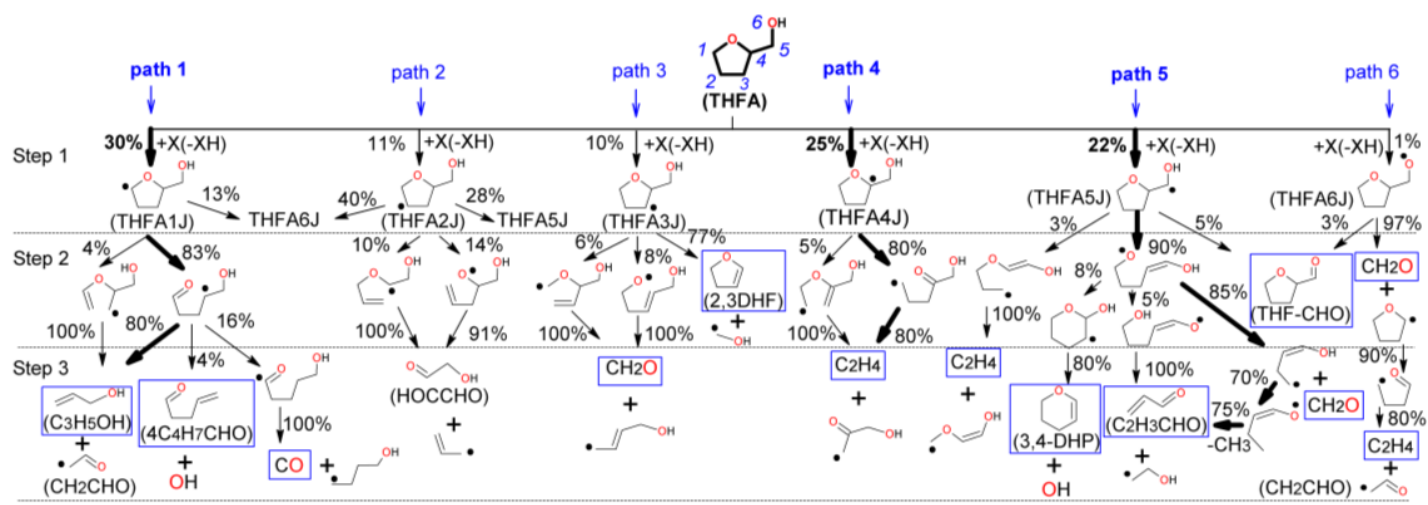

Fig. 4. Main THFA consumption pathways in the studied flame, analyzed at $\sim 70 \%$ THFA conversion $(H A B=2.8 \mathrm{~mm}$, $\mathrm{T} \sim 1100 \mathrm{~K}$ ) using the present model. Percentages given are the relative contributions of the respective pathway to the consumption of given species. Boxes indicate stable species detected in the present experiments. 


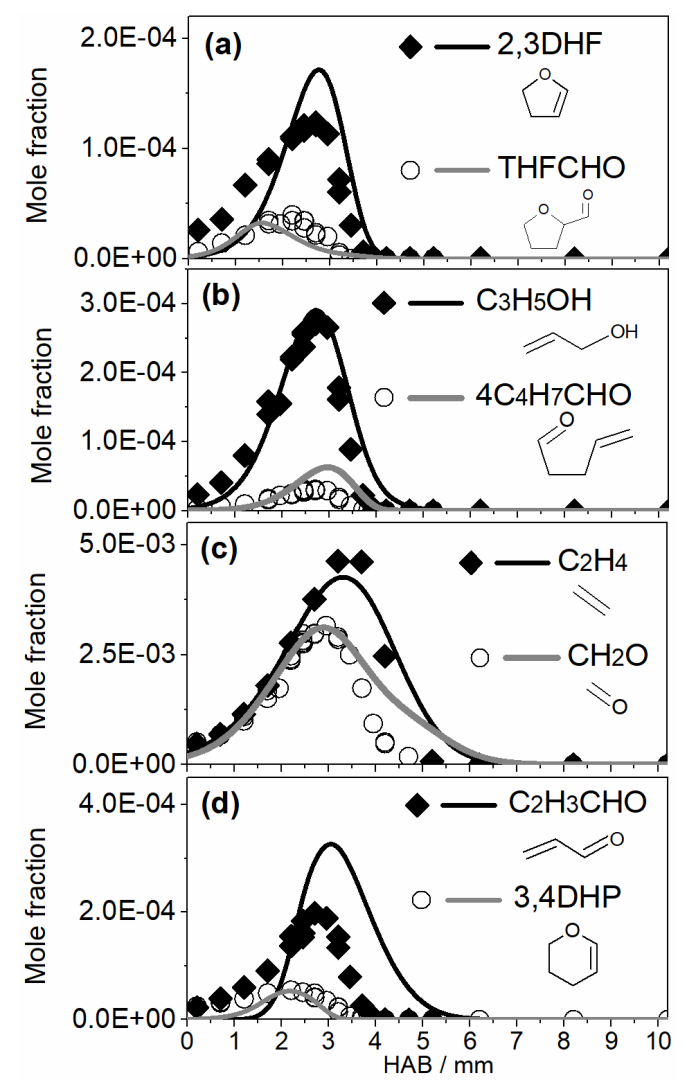

Fig. 5. Profiles of fuel-specific decomposition products highlighted in Fig. 4: (a) 2,3DHF, THFCHO (five member ring species), (b) $\mathrm{C}_{3} \mathrm{H}_{5} \mathrm{OH}, 4 \mathrm{C}_{4} \mathrm{H}_{7} \mathrm{CHO}$ (two species of path 1), (c) $\mathrm{C}_{2} \mathrm{H}_{4}, \mathrm{CH}_{2} \mathrm{O}$ (two species commonly produced by paths 3-6), (d) $\mathrm{C}_{2} \mathrm{H}_{3} \mathrm{CHO}, 3,4 \mathrm{DHP}$ (two species of path 5). Symbols: experiment, lines: present model.

Starting with THFA, $\mathrm{H}$-abstraction reactions by reactive species $\left(\mathrm{X}: \mathrm{H}, \mathrm{OH}, \mathrm{CH}_{3}\right.$, and $\left.\mathrm{O}\right)$ produce six fuel radicals (THF1J-THF6J, see Fig. 4, step 1). $\mathrm{H}$-abstractions at $\mathrm{C}_{\alpha}$ (i.e. $\mathrm{C} 1, \mathrm{C} 4, \mathrm{C} 5$ ) are the most important pathways (constituting $77 \%$ of THFA consumption), which reflects the BDE and rate expression discussed in Section 3.1. The fuel radicals decompose further. Two "early" stable species retain the fuel's cyclic ether structure (2,3DHF and THFCHO, step 2). These species are experimentally detected as abundant intermediates in their mass group (Fig. 3). Their profiles (Fig. 5a) are well reproduced by the present model. Regarding THFA1J (path 1), it partially isomerizes to the THFA6J radical (13\% of its consumption). However, THFA1J decomposes mostly through ring opening, especially via $\mathrm{C}-\mathrm{O} \beta$-scissions (83\%), producing acyclic fuel radicals that dissociate to form $\mathrm{C}_{3} \mathrm{H}_{5} \mathrm{OH}$ and $4 \mathrm{C}_{4} \mathrm{H}_{7} \mathrm{CHO}$. The reaction sequence explains the high amounts of $\mathrm{C}_{3} \mathrm{H}_{5} \mathrm{OH}$ and $4 \mathrm{C}_{4} \mathrm{H}_{7} \mathrm{CHO}$ detected within their respective mass groups (Fig. 3). The good agreement between the model and the experiment (Fig. 5b) indicates that the proposed reaction paths of THFA1J are plausible. Note that CO elimination after isomerization also plays a non-negligible role ( $16 \%$ of fuel radical consumption). THFA2J (path 2) is largely consumed via isomerization to other fuel radicals (68\%). Its ring opening chemistry shares similarities with that of THFA1J and leads to the formation of HOCCHO. However, $\mathrm{HOCCHO}$ could not unambiguously be identified because of its low-resolution MS data and unavailability of the pure product. The predicted maximum $\mathrm{HOCCHO}$ yield is about ten times lower than that of $\mathrm{C}_{3} \mathrm{H}_{5} \mathrm{OH}$ (path 1), hence any failure to identify this species causes only a minor error in the mass and elemental balances. THFA3J (path 3) differs from THFA1J and THFA2J by mainly undergoing a $\mathrm{C}-\mathrm{C} \beta$-scission at the side chain to produce 2,3DHF (77\%). The remaining THFA3J ringopens and contributes partially to $\mathrm{CH}_{2} \mathrm{O}$ formation. $\mathrm{CH}_{2} \mathrm{O}$ is also produced through paths 5 and 6 (Fig. 4). The $\mathrm{CH}_{2} \mathrm{O}$ profile is presented in Fig. $5 \mathrm{c}$ together with $\mathrm{C}_{2} \mathrm{H}_{4}$ which is a primary species produced also via several reaction paths. The model predicts both species profiles very well. Regarding THFA4J (path 4), ring opening reactions are the most important consumption routes and contribute largely to $\mathrm{C}_{2} \mathrm{H}_{4}$ formation. $\mathrm{C}_{2} \mathrm{H}_{4}$ can be also produced via path $5, \mathrm{nC}_{3} \mathrm{H}_{7}$ decomposition, and the reaction 
$\mathrm{C}_{3} \mathrm{H}_{6}+\mathrm{H} \rightarrow \mathrm{C}_{2} \mathrm{H}_{4}+\mathrm{CH}_{3}$. THFA5J (path 5) is consumed via $\beta$-scissions, isomerization, and ring enlargement. These paths contribute to the formation of several detected species such as $\mathrm{C}_{2} \mathrm{H}_{4}$, $\mathrm{CH}_{2} \mathrm{O}, 3,4 \mathrm{DHP}, \mathrm{THFCHO}$, and $\mathrm{C}_{2} \mathrm{H}_{3} \mathrm{CHO}$. These species are the most abundant intermediates in their respective mass groups (Fig. 3). The relative importance of different consumption paths deduced from reaction pathway analysis is consistent with the PES analysis (Fig. 1c) discussed before. Profiles of 3,4DHP and $\mathrm{C}_{2} \mathrm{H}_{3} \mathrm{CHO}$ are presented in Fig. $5 \mathrm{~d}$. The model captures quite well their formation trend. Regarding THFA6J (path 6), it is mostly consumed by $\mathrm{C}-\mathrm{C} \beta$-scission to form $\mathrm{CH}_{2} \mathrm{O}$ and THF radical which in turn decompose via ring opening to $\mathrm{C}_{2} \mathrm{H}_{4}$ and the $\mathrm{CH}_{2} \mathrm{CHO}$ radical.

Some abundant species in their respective group (Fig. 3) do not appear in Fig. 4, e.g. $\mathrm{C}_{3} \mathrm{H}_{6}, \mathrm{CH}_{3} \mathrm{CHO}$, $\mathrm{C}_{2} \mathrm{H}_{5} \mathrm{CHO}$, and $\mathrm{nC}_{3} \mathrm{H}_{7} \mathrm{CHO}$. This suggests that their formation may be not directly controlled by the fuel. Apart from $\mathrm{nC}_{3} \mathrm{H}_{7} \mathrm{CHO}$, the model predicts these species satisfactorily (Fig. $\mathrm{S3}, \mathrm{SM}_{2}$ ). $\mathrm{C}_{3} \mathrm{H}_{6}$ is produced largely from $\mathrm{H}$ addition to $\mathrm{C}_{3} \mathrm{H}_{5} \mathrm{OH}$ followed by $\mathrm{OH}$ elimination (species of path 1), while $\mathrm{CH}_{3} \mathrm{CHO}, \mathrm{C}_{2} \mathrm{H}_{5} \mathrm{CHO}$, and $\mathrm{nC}_{3} \mathrm{H}_{7} \mathrm{CHO}$ originate from the reactions of $\mathrm{CH}_{2} \mathrm{CHO}$ (species of paths 1 and 6 ).

\section{Conclusions}

The composition of a burner stabilized methane flame doped with THFA was analyzed and more than 40 species were identified and quantified. This is the first speciation dataset at combustion conditions acquired for this biofuel. A detailed high-temperature kinetic model was developed to describe the THFA reactions and its derived radicals with the help of high-level first principle calculations. The predictions agree well with the experimental data. The results support that THFA is mainly consumed by $\mathrm{H}$-abstraction reactions. Subsequent reactions of the resulting radicals by $\beta$-scissions or nonnegligible ring enlargement result in a wide spectrum of primary products (e.g. 2,3DHF, THFCHO, 3,4DHP, $4 \mathrm{C}_{4} \mathrm{H}_{7} \mathrm{CHO}, \mathrm{C}_{3} \mathrm{H}_{5} \mathrm{OH}, \mathrm{C}_{2} \mathrm{H}_{3} \mathrm{CHO}, \mathrm{C}_{2} \mathrm{H}_{4}$, and $\mathrm{CH}_{2} \mathrm{O}$ ), which were experimentally observed. Some of these species such as $\mathrm{C}_{2} \mathrm{H}_{3} \mathrm{CHO}$ and $\mathrm{C}_{3} \mathrm{H}_{5} \mathrm{OH}$ exhibit a highly toxic potential. This leads to the need of engine tests to examine this latter trend before THFA can be used safely in practice, and a comparison to other THF biofuels should be also interesting.

\section{Acknowledgments}

The authors thank Dr. F. Louis for helpful discussions regarding model developments. LST thanks the IRePSE institute, the CLIMIBIO and CaPPA projects for financial support. HHC acknowledges I3A for the use of its HPC cluster HERMES and the support of the Aragón government (GPT group T22-20R).

\section{References}

[1] J.-P. Lange, E. van der Heide, J. van Buijtenen, R. Price, Furfural - A promising platform for lignocellulosic biofuels, ChemSusChem. 5 (2012) 150-166.

[2] Z. Yi, H. Xu, D. Hu, K. Yan, Facile synthesis of supported Pd catalysts by chemical fluid deposition method for selective hydrogenation of biomass-derived furfural, Journal of Alloys and Compounds. 799 (2019) 59-65.

[3] W. Leitner, J. Klankermayer, S. Pischinger, H. Pitsch, K. Kohse-Höinghaus, Advanced biofuels and beyond: Chemistry solutions for propulsion and production, Angew. Chem.-Int. Edit. 56 (2017) 5412-5452.

[4] Y. Fenard, H. Song, H. Minwegen, P. Parab, C. Sampaio Mergulhão, G. Vanhove, K.-A. Heufer, 2,5Dimethyltetrahydrofuran combustion: Ignition delay times at high and low temperatures, speciation measurements and detailed kinetic modeling, Combust. Flame. 203 (2019) 341-351.

[5] R. De Bruycker, L.-S. Tran, H.-H. Carstensen, P.-A. Glaude, F. Monge, M.U. Alzueta, F. BattinLeclerc, K.M. Van Geem, Experimental and modeling study of the pyrolysis and combustion of 2methyl-tetrahydrofuran, Combust. Flame. 176 (2017) 409-428. 
[6] L. Cai, H. Minwegen, J. Beeckmann, U. Burke, R. Tripathi, A. Ramalingam, L.C. Kröger, A. Sudholt, K. Leonhard, J. Klankermayer, K.A. Heufer, H. Pitsch, Experimental and numerical study of a novel biofuel: 2-Butyltetrahydrofuran, Combust. Flame. 178 (2017) 257-267.

[7] F. Mathieu, M. Reddemann, D. Martin, R. Kneer, Experimental investigation of fuel influence on atomization and spray propagation using an outwardly opening GDI-injector, SAE Technical Papers 2010-01-2275. (2010).

[8] A. Sudholt, L. Cai, J. Heyne, F.M. Haas, H. Pitsch, F.L. Dryer, Ignition characteristics of a bio-derived class of saturated and unsaturated furans for engine applications, Proc. Combust. Inst. 35 (2015) 2957-2965.

[9] L.-S. Tran, M. Verdicchio, F. Monge, R.C. Martin, R. Bounaceeur, B. Sirjean, P.-A. Glaude, M.U. Alzueta, F. Battin-Leclerc, An experimental and modeling study of the combustion of tetrahydrofuran, Combust. Flame. 162 (2015) 1899-1918.

[10] M.D. Sylla, N. Lamoureux, L. Gasnot, Impact of methyl butanoate oxidation on NO formation in laminar low pressure flames, Fuel. 207 (2017) 801-813.

[11] J. Luque, D.R. Crosley, LIFBASE: Database and Spectral Simulation (Version 1.6), 1999.

[12] M.J. Frisch, G.W. Trucks, H.B. Schlegel, G.E. Scuseria, M.A. Robb, J.R. Cheeseman, G. Scalmani, V. Barone, B. Mennucci, G.A. Petersson, H. Nakatsuji, M. Caricato, X. Li, H.P. Hratchian, A.F. Izmaylov, J. Bloino, G. Zheng, J.L. Sonnenberg, M. Hada, M. Ehara, K. Toyota, R. Fukuda, J. Hasegawa, M. Ishida, T. Nakajima, Y. Honda, O. Kitao, H. Nakai, T. Vreven, J.A. Montgomery, Jr., J.E. Peralta, F. Ogliaro, M. Bearpark, J.J. Heyd, E. Brothers, K.N. Kudin, V.N. Staroverov, R. Kobayashi, J. Normand, K. Raghavachari, A. Rendell, J.C. Burant, S.S. Iyengar, J. Tomasi, M. Cossi, N. Rega, J.M. Millam, M. Klene, J.E. Knox, J.B. Cross, V. Bakken, C. Adamo, J. Jaramillo, R. Gomperts, R.E. Stratmann, O. Yazyev, A.J. Austin, R. Cammi, C. Pomelli, J.W. Ochterski, R.L. Martin, K. Morokuma, V.G. Zakrzewski, G.A. Voth, P. Salvador, J.J. Dannenberg, S. Dapprich, A.D. Daniels, Ö. Farkas, J.B. Foresman, J.V. Ortiz, J. Cioslowski, D.J. Fox, Gaussian 16, Revision B, Gaussian, Inc., Wallingford, CT, 2019.

[13] G.A. Petersson, D.K. Malick, W.G. Wilson, J.W. Ochterski, J.A. Montgomery Jr., M.J. Frisch, Calibration and comparison of the Gaussian-2, complete basis set, and density functional methods for computational thermochemistry, J. Chem. Phys. 109 (1998) 10570-10579.

[14] A.L.L. East, L. Radom, Ab initio statistical thermodynamical models for the computation of third-law entropies, J. Chem. Phys. 106 (1997) 6655-6674.

[15] C.W. Gao, J.W. Allen, W.H. Green, R.H. West, Reaction Mechanism Generator: Automatic construction of chemical kinetic mechanisms, Comput. Phys. Commun. 203 (2016) 212-225.

[16] F. Tureček, (E)- and (Z)-prop-1-en-1-ol: gas-phase generation and determination of heats of formation by mass spectrometry, J. Chem. Soc. Chem. Commun. (1984) 1374-1375.

[17] A.M. Dean, J.W. Bozzelli, Combustion chemistry of nitrogen, in: W.C. Chemistry, Jr. Gardiner (Eds.), Gas-phase Combustion, Springer, NewYork, 2000, p.125-341.

[18] P. Landrieu, F. Baylocq, J.R. Johnson, Etude thermochimique dans la serie furanique, Bull. Soc. Chim. France. (1929) 36-49. Available at NIST chemistry webBook < https://webbook.nist.gov/cgi/cbook.cgi?ID=C97994\&Units=SI\&Mask=1\#Thermo-Gas>

[19] H. Wang, M. Frenklach, Transport properties of polycyclic aromatic hydrocarbons for flame modeling, Combust. Flame. 96 (1994) 163-170.

[20] Chemkin-Pro 2019R1, ANSYS: Canonsburg, PA, 2019. 